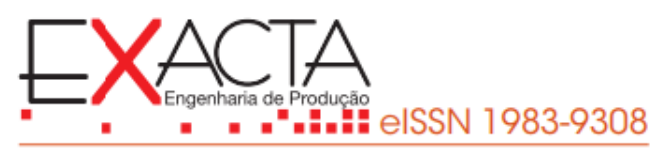

\title{
APROVEITAMENTO DE RESÍDUOS PÓS-CONSUMO PROVENIENTES DE PÁS EÓLICAS UTILIZADAS NA PRODUÇÃO DE ENERGIA: UMA REVISÃO SISTEMÁTICA
}

\section{REUSE OF POST-CONSUMPTION WASTE FROM WIND TURBINE BLADES USED IN ENERGY PRODUCTION: A SYSTEMATIC REVIEW}

Versão do autor aceita publicada online: 13 fev. 2020

Publicado online: 12 maio 2021

Como citar esse artigo - American Psychological Association (APA):

Fernandes, A. P., \& Paiva, J. M. F. (2021, abr./jun.). Aproveitamento de resíduos pós-consumo provenientes de pás eólicas utilizadas na produção de energia: uma revisão sistemática. Exacta, 19(2), 302-323. https://doi.org/10.5585/exactaep.2021.11390.

Submeta seu artigo para este periódico $\bigoplus$

Dados Crossmark 


\title{
APROVEITAMENTO DE RESÍDUOS PÓS-CONSUMO PROVENIENTES DE PÁS EÓLICAS UTILIZADAS NA PRODUÇÃO DE ENERGIA: UMA REVISÃO SISTEMÁTICA
}

\author{
REUSE OF POST-CONSUMPTION WASTE FROM WIND TURBINE BLADES USED IN \\ ENERGY PRODUCTION: A SYSTEMATIC REVIEW
}

\begin{abstract}
${ }^{1}$ Mestre em Engenharia de Produção Universidade Federal de São Carlos - UFSCar andersonp.fernandes@yahoo.com.br

${ }^{2}$ Doutora em Ciência e Engenharia de Materiais Universidade Federal de São Carlos - UFSCar jane@ufscar.br
\end{abstract}

Recebido em: 23 jan. 2019

Aprovado em: 13 fev. 2020
Resumo: A busca por uma matriz energética mais sustentável tem sido foco de vários estudos encontrados na literatura. O presente artigo tem como objetivo compreender o cenário geral do aproveitamento de resíduos provenientes da produção de pás eólicas, utilizadas dentro da indústria de energia eólica, quais processos de aproveitamento estão sendo utilizados na transformação destes materiais e para quais aplicações podem ser destinados. Os resultados demonstram três tipos principais de processos de aproveitamento: o mecânico, o energético e o químico. Dentre as principais aplicações estão a produção de energia pela queima desses resíduos e a reincorporação deles como reforço em novos compósitos. Em virtude do grande volume de pás eólicas produzidas e consequente descarte após final de vida, muito ainda precisa ser estudado como solução para o cenário futuro.

Palavras-chave: Reciclagem. Pás eólicas. Energia eólica. Ciclo-de-vida.

Abstract: The search for a more sustainable energy matrix has been the focus of several studies found in the literature. The objective of this article is to understand the general scenario of the reuse of waste from the production of wind turbines, used within the wind energy industry, which reuse processes are being used in the transformation of these materials and for which applications may be intended. Results appoint three main types of reuse processes: mechanical, energetic, and chemical. Among the main applications are energy productions by the burning of wastes and their reincorporation as reinforcement in new composites. Due to the large volume of wind turbines produced and consequent disposal after end of life, much still need to be studied as solution for the future scenario.

Keywords: Recycling. Wind blades. Wind power. Life cycle. 


\section{Introdução}

As fontes de energias renováveis, neste caso particular a energia eólica, vêm despertando muito interesse, uma vez que o uso de energias limpas segue uma tendência no mundo inteiro (Yazdanbakhsh, Bank, Rieder, Tian, \& Chen, 2018). Parte dos investimentos feitos nesta área visa suprir o aumento da demanda energética mundial e parte deles visa minimizar os impactos ambientais oriundos dos meios de captação tradicionais de energia, como degradação ao meio ambiente, esgotamento de recursos naturais e aquecimento global. "Durante as últimas décadas, o aumento da conscientização sobre questões ambientais tem sido um fator determinante no desenvolvimento de recursos de energia renovável com menor impacto ambiental, tais como hidrelétrica, solar e eólica" (Andersen, Eriksson, Hillman, \& Wallhagen, 2016).

Os investimentos feitos em tecnologias avançadas na busca pela transição das matrizes energéticas implicam no desenvolvimento de novos processos de geração, bem como novos materiais e dispositivos utilizados para este fim. Porém, tais tecnologias carregam consigo alguns tipos de resíduos de fabricação ou pós-consumo, que se não tratados adequadamente podem ser tão maléficos ao meio ambiente quanto aqueles tradicionalmente utilizados (Andersen et al., 2016; Guerrero, Mancini, \& Toubia, 2011).

Apoiando-se no exemplo das indústrias de energia eólica pode ser verificado um crescimento contínuo na utilização desta matriz energética, o que representa aumento na fabricação de pás para as turbinas geradoras e que, por sua vez, constituem um problema ainda complexo, pois são produzidas a partir de compósitos termorrígidos e de difícil aproveitamento (Cherrington et al., 2012).

A energia eólica desenvolveu-se rapidamente nas últimas duas décadas para se tornar uma das fontes de energias renováveis mais promissoras e economicamente viáveis para alguns países. Embora a energia eólica seja reivindicada para fornecer energia renovável limpa sem emissões durante a operação, este é apenas um dos lados da moeda. "As pás, um dos componentes mais importantes nas turbinas eólicas, feitas com compósitos, são atualmente consideradas não recicláveis" (Liu, P., \& Barlow, 2017)

A herança a ser deixada pelas usinas eólicas após o ciclo de vida útil representa um grande desafio ambiental e que necessita de tratativa imediata, caso contrário perderão o intuito ou finalidade de energia limpa. As primeiras instalações comerciais de turbinas eólicas se aproximam do fim do ciclo de vida e o problema da eliminação das pás eólicas começa a emergir como um fator significativo para o futuro (Liu, P., \& Barlow, 2017).

A estrutura das pás eólicas, em geral, é constituída de compósitos poliméricos termorrígidos reforçados com tecidos de fibras de vidro, que são materiais denominados estruturais ou avançados. Tais compósitos avançados exibem propriedades físicas e químicas desejáveis para as pás eólicas, 
porque apresentam alta rigidez e resistências mecânicas à tração, à flexão, compressão, impacto, estabilidade dimensional, resistências química e térmica, além de processamento relativamente fácil (Goren \& Atas, 2008).

A gestão destes tipos de resíduos é um problema recente visto que a evolução do setor de energia eólica ainda não gerou uma quantidade significativa de material. Estima-se que a vida útil das pás eólicas seja em torno de 20 a 30 anos (Yazdanbakhsh et al., 2018); portanto, os primeiros parques eólicos instalados iniciam o processo de descomissionamento. A partir de 2020 serão gerados aproximadamente 50.000 toneladas por ano de resíduos de pás eólicas em fim de ciclo de vida (Liu, P., \& Barlow, 2017).

Neste contexto, este estudo tem como objetivo traçar um panorama do aproveitamento de resíduos pós-consumo provenientes de pás eólicas utilizadas para geração de energia eólica, visando preencher lacunas da literatura específica em relação aos tipos de processos e as alternativas para tais aplicações.

\section{Metodologia de pesquisa}

Nesta seção está detalhada a metodologia utilizada para o desenvolvimento da revisão bibliográfica sistemática (RBS) proposta no trabalho. A revisão da literatura visou explorar as contribuições já feitas nesta área do conhecimento, buscando solucionar as questões aqui propostas. Para tanto, foram utilizados como diretrizes, os tópicos abordados por Tranfield (Tranfield, Denyer, \& Smart, 2003) em uma revisão sistemática da literatura tendo como foco o reaproveitamento de resíduos provenientes da produção de pás eólicas.

\subsection{Questões da pesquisa}

Dentre os objetivos desta revisão bibliográfica sistemática (RBS), destacam-se a reunião e entendimento dos métodos existentes para análise de alternativas de reaproveitamento de resíduos. A partir das informações buscou-se compreender o atual cenário da reciclagem de resíduos dentro indústria de energia eólica, assim como os processos de reaproveitamento que estão sendo utilizados na transformação destes materiais e também para quais aplicações podem ser destinados. A seguir estão apresentados os questionamentos utilizados como base para a exploração e discussão da literatura disponível.

Q1: Qual é o cenário geral de reaproveitamento de resíduos provenientes da produção de pás eólicas?

Q2: Quais processos de reaproveitamento vêm sendo utilizados?

Q3: Em quais aplicações os resíduos de pás eólicas podem ser utilizados? 


\title{
2.2 Estratégia de pesquisa
}

Faz-se indispensável a definição de uma estratégia de pesquisa, para que se tenha uma RBS adequada. Assim, a estratégia utilizada neste trabalho foi composta pelas seguintes etapas:

\author{
i. criar consultas para pesquisa em banco de dados \\ ii. coletar e resumir toda a informação recolhida \\ iii. criar critérios de inclusão e exclusão \\ iv. coletar dados \\ v. analisar dados \\ vi. limitações
}

\subsubsection{Método de pesquisa}

O estudo foi baseado nas publicações disponíveis nas bases científicas: Web of Science, Scopus e Scielo. O processo de pesquisa ao longo de todo este trabalho foi feito com foco nos artigos publicados a partir do ano de 2008.

\subsubsection{Termos de pesquisa: consultas}

Neste tópico foram realizadas consultas a fim de pesquisar e obter informações específicas das bibliotecas contidas nos bancos de dados científicos citados. Estas consultas foram realizadas com a utilização de palavras-chave referentes aos questionamentos propostos, iniciando com uma pesquisa abrangente sobre reciclagem de resíduos e refinando-a ao longo das etapas. Deste modo, a primeira consulta de pesquisa, aqui chamada de CP1 foi:

\section{CP1. ("Waste recycling" or "Polymer recycling")}

Visando registrar a quantidade de documentos científicos que permeiam o tema, estas consultas encontraram 3.336 resultados nas bases de dados. Sendo este número bastante elevado devido à amplitude do tema em questão, foram inseridas mais restrições a fim de obter as informações apropriadas.

CP2. ("Waste recycling" or "polymer recycling") and ("wind blade" or "wind turbine blade")

A inclusão de referenciais do segmento eólico reflete os objetivos do estudo, de investigar o cenário de reaproveitamento de resíduos aplicados a esta área, tendo em vista os questionamentos anteriormente levantados. Esta pesquisa retornou 44 resultados.

Com o intuito novamente de refinar a busca, tendo em vista informações mais relevantes para o tema definido ou ainda eliminar possíveis lacunas da pesquisa, novas consultas foram feitas. 
A fim de documentar todos os procedimentos e consultas realizadas, estas são detalhadas a seguir:

CP3. "Wind blade recycling"

CP4. ("recycling" OR "recycled") AND ("wind blade" OR "wind turbine blade")

CP5. ("recycling" OR "recycled") AND "wind power"

CP6. "reuse" AND ("wind blade" OR "wind turbine blade")

Após refinamento da pesquisa obteve-se o número de 33 artigos, dos quais 18 estavam disponíveis (full text) para consulta e download. Estes foram, então, os artigos selecionados para a RBS. Ressalta-se ainda que em todas as buscas, os arquivos em questão tiveram ano de publicação a partir de 2008.

\subsection{Critérios de inclusão e exclusão}

Para que os trabalhos selecionados fossem coerentes com o estudo proposto, alguns critérios de inclusão e exclusão foram utilizados, auxiliando na filtragem dos estudos irrelevantes. Ressalta-se que alguns dos critérios de exclusão já foram inseridos na fase de consulta, conforme citado a seguir.

\subsubsection{Critérios de exclusão}

Artigos publicados antes de 2008;

- Outra forma de publicação que não artigo;

- Artigos não relacionados à reciclagem de resíduos ou polímeros;

- Artigos não relacionados à reciclagem no segmento de energia eólica;

- Artigos duplicados (disponíveis em várias bases de dados);

- Artigos indisponíveis para consulta e download.

\subsubsection{Critérios de inclusão}

- Artigo que fornece informações sobre o panorama da reciclagem no segmento eólico;

- Artigo que propõe alternativas de reprocessamento dos resíduos de pás eólicas;

- Artigo que discute descarte e ciclo-de-vida de pás eólicas.

A aplicação destes critérios levou em conta que se pelo menos um critério de exclusão fosse aplicado ao artigo, este seria eliminado. Após este processo, avaliaram-se os critérios de inclusão, no qual o artigo deveria se encaixar em pelo menos um dos itens. 
Ressalta-se, ainda, que estes critérios foram aplicados com base na leitura do título e resumo dos artigos selecionados por meio das consultas. Além disso, visando facilitar este processo de aplicação dos critérios, utilizou-se a plataforma Mendeley para melhor organização e facilidade durante a escolha dos artigos.

Dessa forma, após a aplicação dos critérios de inclusão e exclusão, foram selecionados 15 artigos para compor a RBS.

\subsection{Desvio do procedimento}

Tendo em vista as informações adquiridas ao longo das etapas propostas pela metodologia RBS, as consultas, critérios e hipóteses inicialmente levantadas foram sofrendo modificações visando melhorar a qualidade do presente trabalho. Assim, torna-se válido ressaltar que os subtópicos anteriores apresentam somente o procedimento final utilizado. Os artigos selecionados e devidamente agrupados serão apresentados e discutidos na seção subsequente.

\section{Resultados}

A partir dos 15 artigos completos selecionados para extração de dados, este tópico visou responder as questões propostas anteriormente neste artigo.

\subsection{RQ1. Qual é o cenário geral de reaproveitamento de resíduos provenientes da produção de pás eólicas?}

\subsubsection{A energia eólica no mundo}

O segmento de energia eólica tem se apresentado como promissor no século 21. A capacidade instalada desta matriz energética saltou de 7.600 MegaWatts (MW) em 1998 para 364.270 MW em 2014 (Liu, P., \& Barlow, 2017). Estima-se ainda um crescimento médio anual de 12\% deste mercado até o ano de 2026 (Andersen et al., 2016). A evolução da capacidade de energia eólica instalada no mundo pode ser observada na figura 1. 
Figura 1 - Capacidade anual de energia eólica instalada no mundo

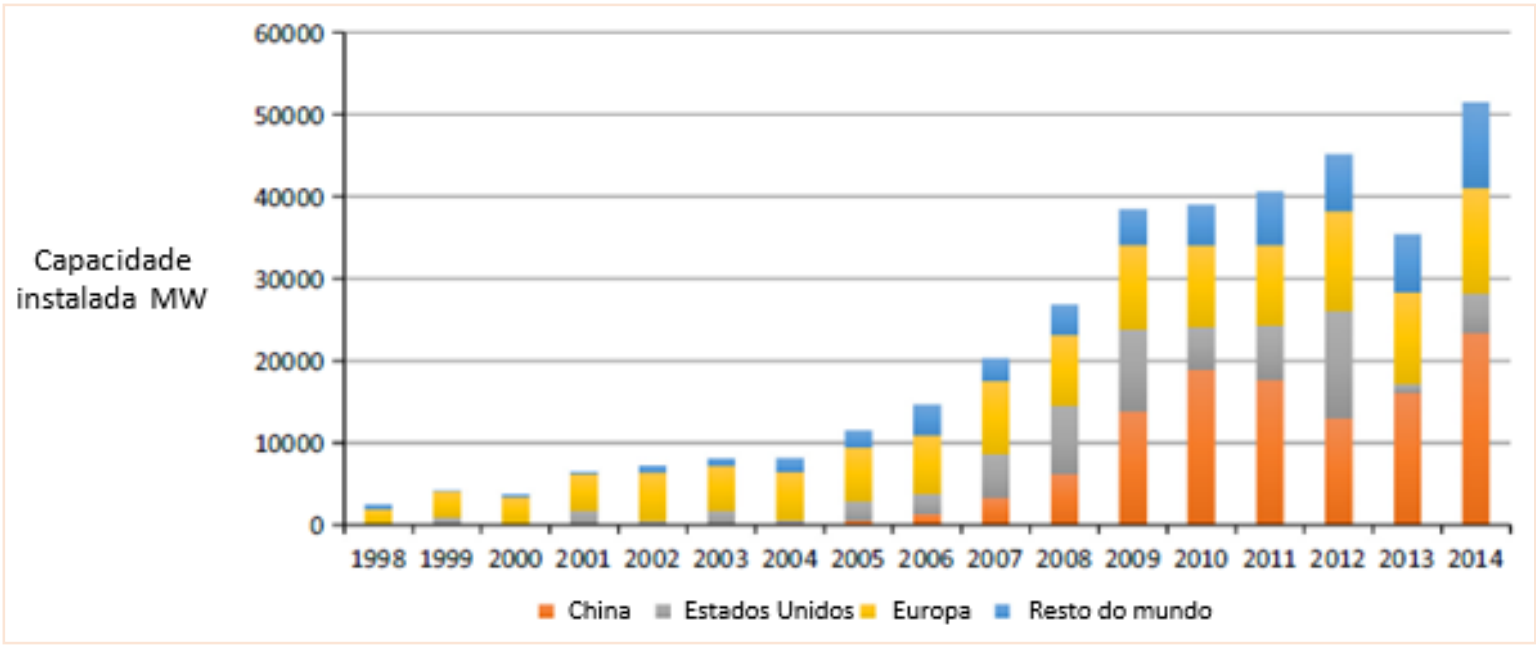

Fonte: (Liu, P., \& Barlow, 2017).

Como observado, a China é o principal investidor do segmento eólico e responde por cerca de 35\% da capacidade mundial instalada. O Brasil atualmente ocupa a oitava posição no ranking representando $2 \%$ do total mundial, aproximadamente, $13 \mathrm{GW}$.

As projeções nacionais e internacionais permitem afirmar que a demanda por aerogeradores irá intensificar-se mundo afora. O Conselho Global de Energia Eólica tinha perspectivas de que o crescimento anual global da energia eólica seria superior a 12\% entre 2013 e 2018, (Liu, P., \& Barlow, 2017), e os dados consolidados até o fim de 2018 apontam um incremento de 227GW na capacidade total instalada, que reflete um aumento da ordem de $62 \%$ no período ou $12,4 \%$ na média anual (GWEC, 2019). Associado ao crescimento da energia eólica observa-se também um aumento da quantidade de resíduos gerados na fabricação das pás, assim como no descarte de pás após o final de vida útil, (Guerrero et al., 2011). 


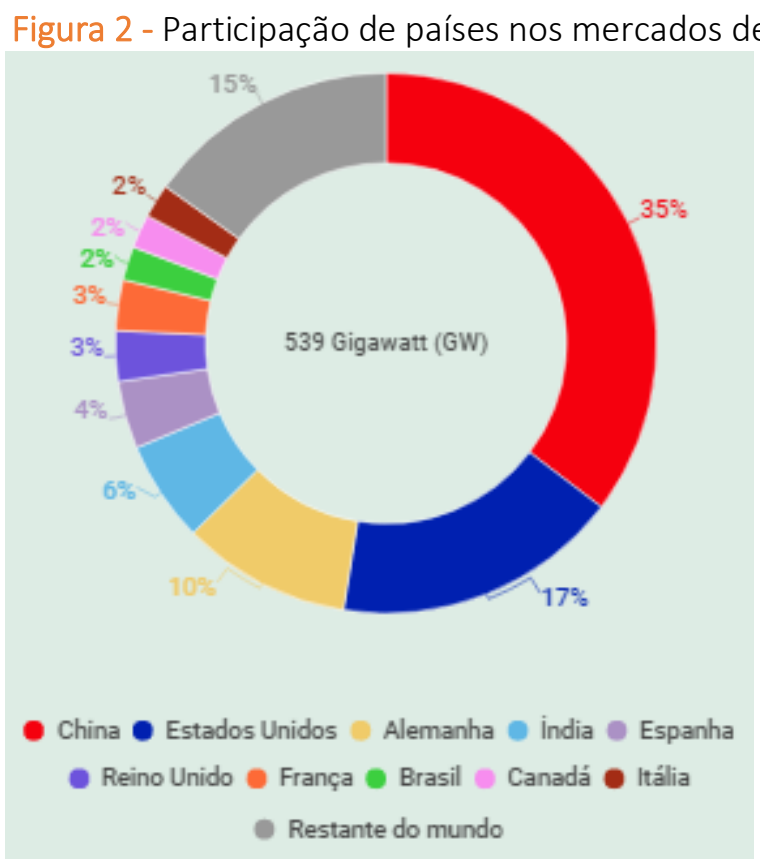

Fonte: (GWEC, 2019).

Estudos pós-utilização indicam que a partir de 2020 serão geradas 50.000 toneladas por ano de resíduos provenientes dos parques eólicos, com pouca ou nenhuma solução que não o descarte final; número que tende a exceder 200.000 toneladas em 2034 (Liu, P., \& Barlow, 2017).

Já as figuras 3 e 4 apresentam respectivamente as estimativas de demanda de material a ser consumido na produção de pás eólicas e de resíduos gerados a partir desta produção, ambas estendidas até o ano de 2050 (Liu, P., \& Barlow, 2017).

A projeção de consumo de material a ser utilizado na construção dos novos parques eólicos (figura 3) indica um aumento de aproximadamente 2,8 milhões de toneladas nos próximos 30 anos, aumento gradual de cerca de 90 mil toneladas por ano. 
Fernandes, A. P., \& Paiva, J. M. F. (2021, abr./jun.). Aproveitamento de resíduos pós-consumo provenientes de pás eólicas utilizadas na produção de energia: uma revisão sistemática

Figura 3 - Consumo de material para fabricação de pás de aerogeradores

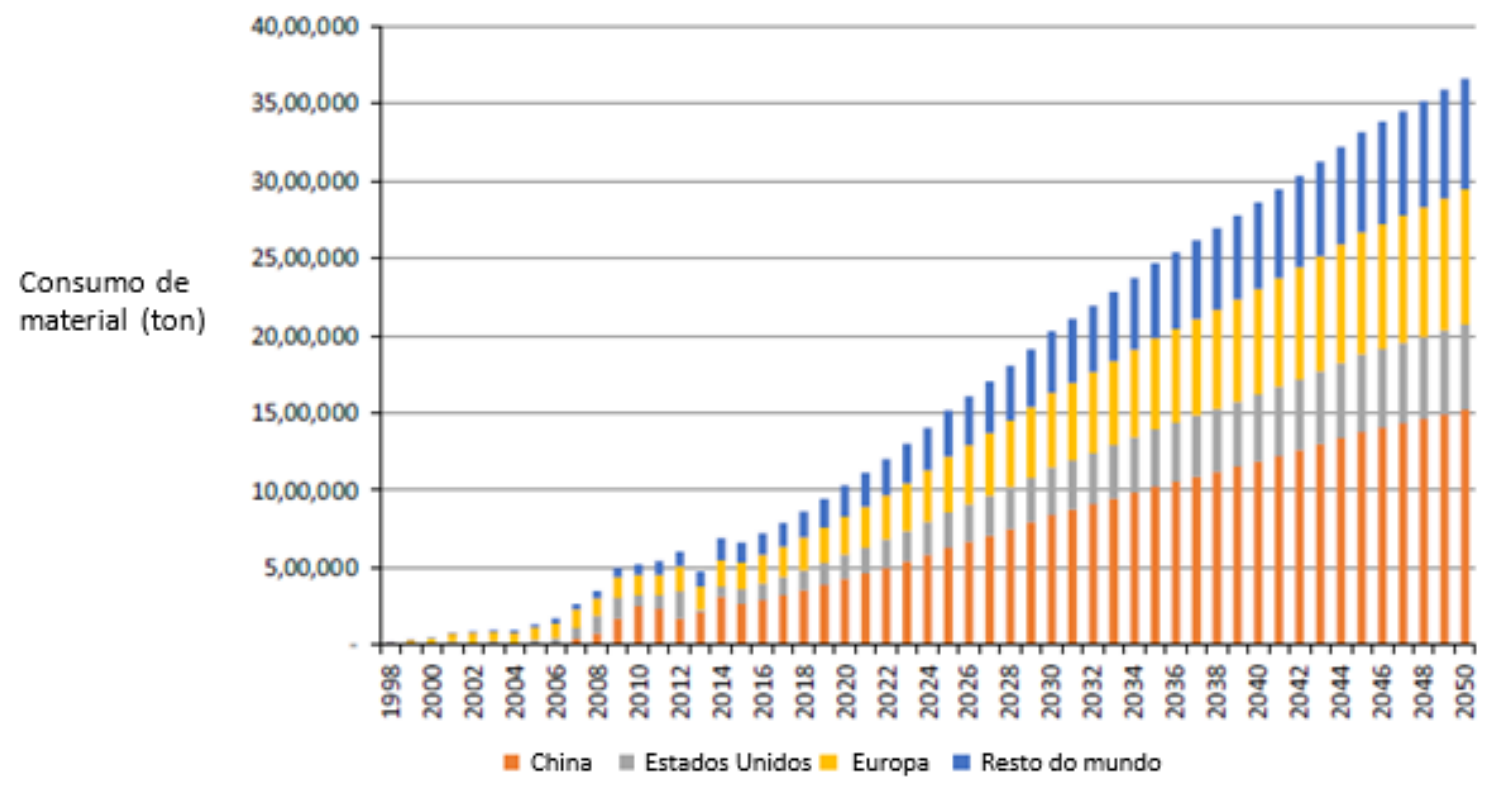

Fonte: (Liu, P., \& Barlow, 2017).

Como consequência do consumo, a geração de resíduos provenientes das intalações dos parques também será incrementada (figura 4). Calcula-se aproximadamente 1,4 milhões de toneladas a mais nos próximos 30 anos ou cerca de 45 mil toneladas a cada ano.

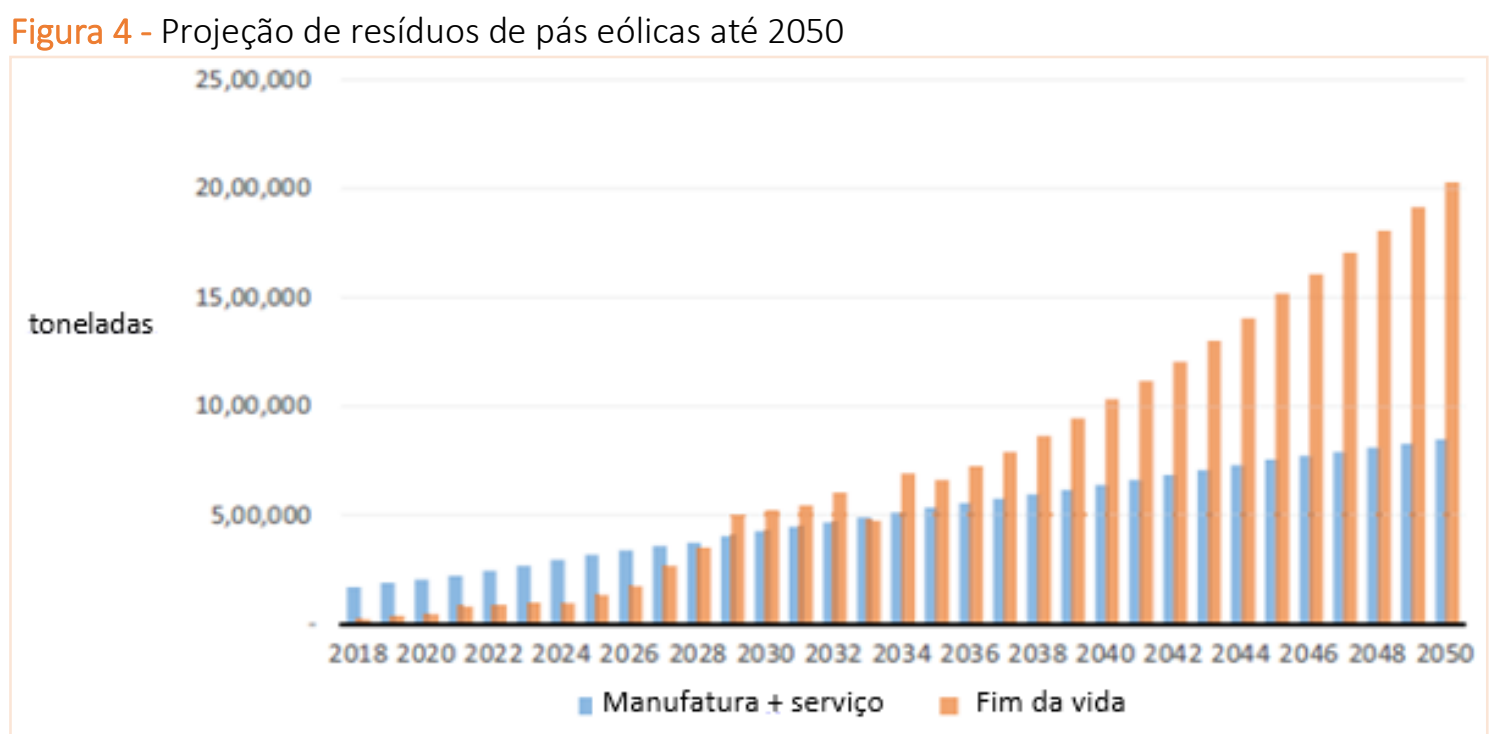

Fonte: (Liu, P., \& Barlow, 2017).

No geral, estima-se que em 2050 para cada 1 tonelada de material utilizado na fabricação dos aerogeradores, será produzida em contrapartida 0,5 tonelada de resíduo. Diante de um quadro alarmante como este, principalmente se considerada a origem complexa destes materiais, uma vez que possuem estruturas de difícil tratativa, nas seguintes seções deste artigo será feita análise do cenário atual de reciclagem no segmento. 


\subsubsection{Reciclagem de resíduos do segmento eólico}

Conforme os resultados de estudos e pesquisas considera-se como técnicas de reciclagem mais adequadas para compósitos de matriz polimérica termorrígida (um dos constituintes das pás eólicas), a reciclagem energética, a reciclagem química e a reciclagem mecânica.

Tanto a reciclagem energética quanto a química podem ser aplicadas em polímeros convencionais, tais como termoplásticos e elastômeros (Ramirez-Tejeda, Turcotte, \& Pike, 2017). Já a reciclagem mecânica é utilizada para polímeros termoplásticos fusíveis, que são diferentes dos compósitos termorrígidos utilizados na fabricação das pás eólicas.

\section{- Reciclagem energética}

A reciclagem energética é a queima controlada de um material, que visa aproveitar a energia que ele oferece após uma reação de combustão, que quando completa, produz dióxido de carbono e água, sendo possível aplicar em qualquer polímero, como em outros materiais que contenham carbono, como papéis, vegetais, etc (Cherrington et al., 2012). Isso significa que após o processo de finalização do material nada mais poderá ser feito. Além de problemas ambientais causados pelos gases emanados, a queima de pás tem seus inconvenientes econômicos, pois a quantidade de fibras de vidro, equivale a aproximadamente $70 \%$ não-combustível, e isso inviabiliza o retorno econômico de uma usina que visa obter calor para depois produzir eletricidade por intermédio do vapor de água.

As pás fabricadas geralmente possuem fibras de vidro com potencial calorífico baixo, o que torna inviável sua utilização, porém estima-se que o teor de fibras de vidro possa diminuir ao longo dos próximos 50 anos, o que ainda representa pouco para tornar esse material um combustível atraente (Cherrington et al., 2012).

\section{- Reciclagem química}

A reciclagem química é aquela que emprega calor e agentes químicos com o objetivo de romper ligações intramoleculares ou intermoleculares. De acordo com o polímero e as condições de reação, podem ser geradas uma infinidade de produtos, que com o processo de decomposição química dará origem a moléculas menores, como líquidos combustíveis e gases que podem ser reaproveitados em outro processo químico (Beauson, Madsen, Toncelli, Brøndsted, \& Ilsted Bech, 2016).

Para os termorrígidos, como o epóxi das pás de aerogeradores, o número de ligações cruzadas (crosslinking) é relativamente alto em relação a um elastômero, o que faz com que o rompimento destas ligações cruzadas dos termorrígidos seja bem mais complexo, quase que impossível.

$\mathrm{Na}$ tentativa de aproveitamento dos termorrígidos, os esforços estão sendo voltados ao desenvolvimento da pirólise à vácuo, na qual o calor é o principal responsável pela quebra das ligações 
cruzadas. Em reações desse tipo, ligações intramoleculares também são quebradas e o produto final dificilmente é um monômero útil, mas geralmente um óleo ou gás de poder calorífico interessante para queimas posteriores (Guerrero et al., 2011).

As principais vantagens da realização do processo de pirólise são as possibilidades de se recuperar as fibras presentes com maior qualidade, pois não foram submetidas a condições tão críticas de reação, como temperatura, oxigênio e outros reagentes. Já no caso de ser à vácuo, o menor tempo de residência do vapor no reator reduz a ocorrência e intensidade de reações secundárias, como a oxidação.

\section{- Reciclagem Mecânica}

A reciclagem mecânica é feita com a trituração de resíduos de materiais compósitos que podem ser utilizados como carga de reforço em novas matrizes poliméricas, ou seja, os materiais reciclados passam por um processo de alteração física, em geral de estruturas sólidas para pó, provenientes de uma série de etapas operacionais de reaproveitamento.

A reciclagem mecânica consiste na conversão dos materiais pós-industriais ou pós-consumo descartados, podendo ser reutilizados na produção de novos produtos, como, pisos, embalagens nãoalimentícias, entre outros usos. Para a fabricação de pás eólicas a incorporação de resíduos pode ser vista como uma opção já que o processo de fabricação gera quantidade significativa de partículas que podem ser capturadas e classificadas. "O grande desafio está na moagem e fragmentação adequada para redução de pedaços grandes de resíduos como no caso da reciclagem de uma pá inteira" (Beauson et al., 2016).

O processo mecânico para propiciar o uso de um resíduo como carga de reforço é baseado na redução do tamanho ou imposição de grandes partes ou pedaços em frações menores. "No caso de compósitos de fibras de vidro, o material é normalmente reduzido por meio de equipamento de corte em baixa rotação dando origem a partículas que, posteriormente, precisarão ser classificadas pelo tamanho" (Novais, Carvalheiras, Seabra, Pullar, \& Labrincha, 2017).

A seguir é apresentado um quadro resumo de seção visando responder o questionamento proposto em RQ1. 
Quadro 1 - Cenário do reaproveitamento dos resíduos pós-consumo da utilização de pás eólicas

\begin{tabular}{|c|c|c|}
\hline Resíduos & $\begin{array}{l}\text { Métodos de } \\
\text { reciclagem }\end{array}$ & Características \\
\hline \multirow[t]{3}{*}{$\begin{array}{l}\text { Compósitos termorrígidos } \\
\text { - Matriz polimérica } \\
\text { - Fibras de vidro }\end{array}$} & Energética & $\begin{array}{l}\text { - Queima controlada do material } \\
\text { - Energia gerada por reação de combustão } \\
\text { - Degradação completa do material (irreversível) } \\
\text { - Baixo poder calorífico (70\% não-combustível) } \\
\text { - Liberação de gases tóxicos pela queima }\end{array}$ \\
\hline & Química & $\begin{array}{l}\text { - Uso de reagentes químicos } \\
\text { - Rompimento de ligações moleculares } \\
\text { - Técnica de pirólise à vácuo } \\
\text { - Melhor qualidade das fibras recuperadas }\end{array}$ \\
\hline & Mecânica & $\begin{array}{l}\text { - Trituração dos resíduos } \\
\text { - Fragmentação dos resíduos em partículas menores } \\
\text { - Classificação das partículas por tamanho } \\
\text { - Utilização das partículas em novas matrizes } \\
\text { poliméricas }\end{array}$ \\
\hline
\end{tabular}

Fonte: Elaborado pelos autores.

\subsection{RQ2. Quais processos de reaproveitamento vêm sendo utilizados?}

A diretriz de aterro sanitário da UE (1999) estabelece metas para reduzir progressivamente o nível de resíduos biodegradáveis destinados a aterros sanitários e proíbe o descarte em aterro comum de certos resíduos perigosos, como resíduos líquidos, resíduos clínicos e pneus usados. Cada país interpreta de forma diferente as diretrizes para aplicar critérios e procedimentos para a aceitação de resíduos em aterros sanitários. Dessa maneira, materiais com alto conteúdo orgânico proveniente de resinas poliméricas, como as pás eólicas, que contêm cerca de 30\% de conteúdo de matriz epóxi, tornase necessário encontrar alternativas após o fim das suas vidas úteis, e aí surge o interesse na reciclagem deste tipo de material (Cherrington et al., 2012).

O termo reciclagem pode ser definido como uma operação de recuperação, pela qual os materiais residuais são reprocessados em produtos, materiais ou substâncias para serem utilizados em novas aplicações. "A reciclagem das pás eólicas pode ter vários significados, resultando em diferentes soluções" (Andersen, Bonou, Beauson, \& Brønsted, 2014).

A reciclagem pode ser entendida como um processo de renovação, no qual as lâminas são retiradas, reparadas e reutilizadas, ou como uma operação de reprocessamento para extrair e reutilizar os diferentes materiais presentes nas pás em outros processos. A reciclagem também pode significar a 
extração das fibras de vidro do compósito, a fim de reutilizar esses resíduos sólidos em novos compósitos poliméricos (Åkesson, Foltynowicz, Christéen, \& Skrifvars, 2012).

Técnicas para recuperar as fibras de vidro e a resina epóxi vêm sendo investigadas há cerca de 20 anos, sendo que algumas dessas técnicas já foram aplicadas em escala comercial. Porém, sua viabilidade econômica ainda precisa ser provada e colocada em prática. Essas técnicas podem ser divididas em três categorias principais, baseando-se nos tipos de processos envolvidos, que são os processos mecânicos, térmicos e químicos (Andersen et al., 2014).

\subsubsection{Processo mecânico}

O processamento mecânico é um método de descarte e reaproveitamento relativamente simples, ele consiste no corte e moagem do material da composição das pás. Este processo demanda uma grande quantia de energia e resulta em pedaços ou pequenas partículas de fibra de vidro. Porém essas partículas apresentam propriedades mecânicas pobres, devido ao menor comprimento e por terem sido submetidas à tamanha energia e cisalhamento durante seu processamento. Assim, tais partículas acabam sendo utilizadas apenas como material de "enchimento" nas indústrias do cimento e do asfalto. A Figura 5 mostra simplificadamente o material nas diferentes partes desse processo (Ramirez-Tejeda et al., 2017).

O baixo preço de mercado para materiais de reuso, o custo elevado das retificadoras e a grande quantia de energia necessária para essas operações tem limitado o custo-benefício do uso desses compostos termofixos. (Andersen et al., 2014). Além disso, a poeira emitida no processo de moagem das pás eólicas trás riscos à saúde e segurança dos trabalhadores que realizam o processo. O contato com essa poeira pode causar irritações na pele e olhos, em caso de inalação, o trabalhador pode sentir irritação nas mebranas mucosas e tosses (Beauson, Lilholt, \& Brøndsted, 2014).

Figura 5 - Fotografia de pá eólica submetida ao processo mecânico

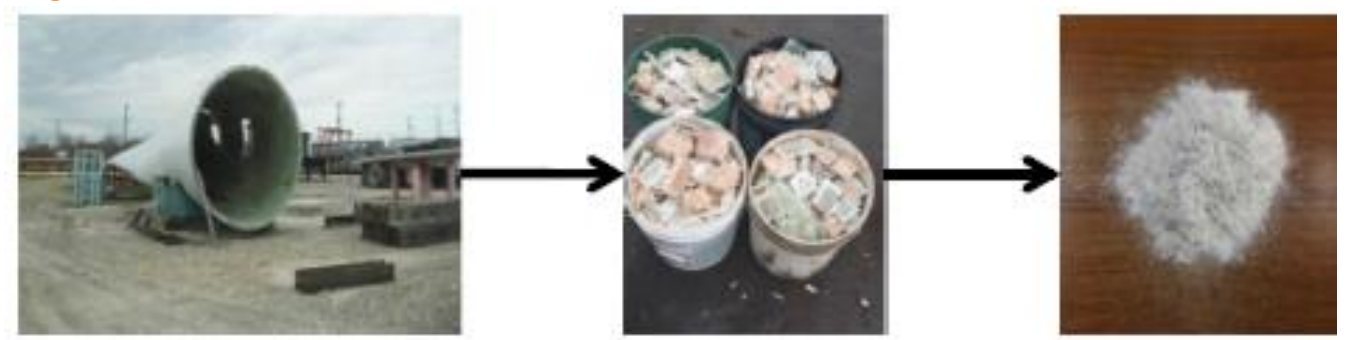

Fonte:

(Mamanpush et al., 2018).

A inalação e exposição prolongadas às partículas presentes na poeira podem causar alterações em componentes celulares e enzimáticos dos pulmões humanos, causando uma irritação pulmonar conhecida como alveolite aguda. Apesar de existirem vários recursos tecnológicos para minimizar os 
Fernandes, A. P., \& Paiva, J. M. F. (2021, abr./jun.). Aproveitamento de resíduos pós-consumo provenientes de pás eólicas utilizadas na produção de energia: uma revisão sistemática

impactos negativos dessa exposição humana à poeira, como é o caso de tecnologias de filtração por sucção, umidificação do local de corte e o encapsulamento do processo de moagem, estes recursos tornam o processamento mecânico ainda mais caro, tornando seu custo benefício menor (RamirezTejeda et al., 2017).

Por isso ainda é necessário que se realizem mais pesquisas sobre a eficácia dessas tecnologias que minimizam os impactos dessa exposição e sobre o risco de doenças respiratórias que estão relacionadas à exposição a partículas das fibras e da resina resultantes no processo (Ramirez-Tejeda et al., 2017).

\subsubsection{Processo térmico}

A incineração das pás eólicas é um método de descarte com potencial para recuperação de material e energia, a incineração dos compostos termofixos possui algumas vantagens, como economia de espaço físico no processo e de valor econômico, já que durante a queima, a resina age como um gerador de calor durante a recuperação da fibra de vidro. Uma vez que a fibra de vidro não atua como combustível, o valor calorífico irá depender da proporção de resinas poliméricas presentes (RamirezTejeda et al., 2017).

Apesar de apresentar tais vantagens, há importantes fatores ambientais envolvidos nesse processo, a combustão dos compósitos reforçados com fibras de vidro é especialmente problemática, pois pode produzir gases tóxicos, fumaça e fuligem, que são prejudiciais ao meio ambiente e aos seres humanos. Isso ocorre devido a problemas na etapa de limpeza dos gases, e é causado pela presença de pequenas frações de fibras de vidro e outros poluentes (Cherrington et al., 2012).

O monóxido de carbono $(\mathrm{CO})$ e o formaldeído $\left(\mathrm{CH}_{2} \mathrm{O}\right)$ são resíduos da degradação térmica da resina epóxi, outro resíduo é o dióxido de carbono, que apesar de não ser tóxico, quando liberado na atmosfera pode contribuir para o aquecimento global, por meio do efeito estufa. Além disso, cerca de $60 \%$ da sucata permanece como cinzas poluentes após o processo de incineração, tendo que ser enviados para aterros adequados (Ramirez-Tejeda et al., 2017).

Outros métodos de processamento energéticos conhecidos são a Pirólise e a Combustão em Leito Fluidizado (FBC), estes processos visam a recuperação de ambos componentes, a fibra de reforço e a resina, porém também pode recuperar o calor de combustão a partir de um sistema de recuperação.. O processo de pirólise decompõe o material orgânico em substâncias de baixa massa molar, e isso ocorre em um ambiente sob condições controladas, onde não há presença de oxigênio (Larsen, 2009).

Na Figura 6 está apresentado um esquema do processo de pirólise, enquanto na Figura 7 é mostrado o "antes e depois" de uma pá eólica que passa por esse processo (K. Larsen, 2009). A resina 
Fernandes, A. P., \& Paiva, J. M. F. (2021, abr./jun.). Aproveitamento de resíduos pós-consumo provenientes de pás eólicas utilizadas na produção de energia: uma revisão sistemática

ou polímero degradado, que agora está em forma de moléculas menores, podendo ser um óleo, gás ou carvão sólido, poderá ser utilizado como fonte de energia em outros processos, enquanto a fibra de vidro é recuperada intacta. A Combustão em Leito Fluidizado (FBC) é outro método que consiste em misturar o combustível e ar em uma proporção específica para obter uma combustão ordenada (Andersen et al., 2014).

Figura 6 - Esquema do processo de pirólise

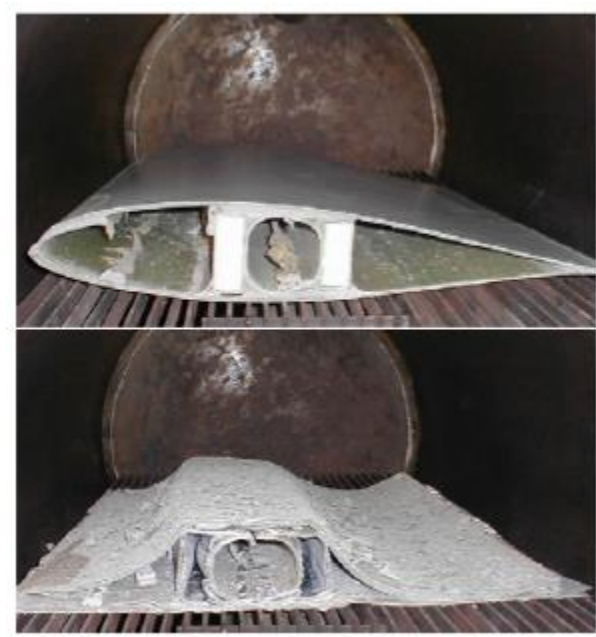

Fonte: (Larsen, 2009).

Figura 7 - Fotografias do "antes e depois" de uma pá eólica submetida ao processo de pirólise.

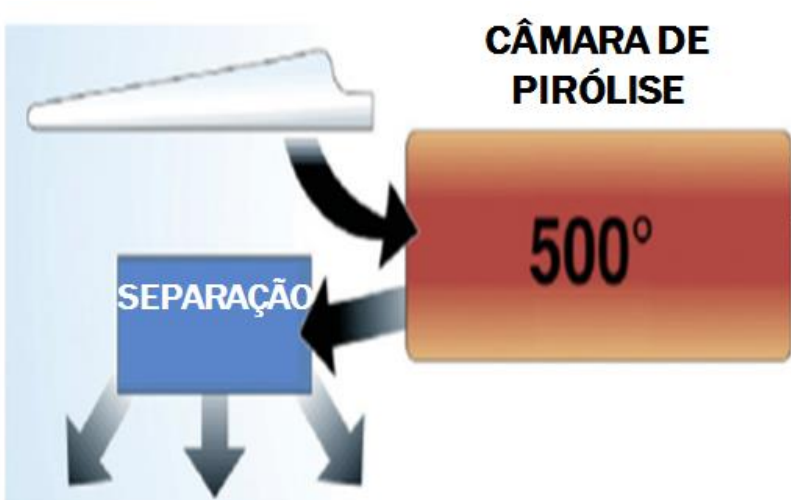

VIDRO METAL ENCHIMENTO

\section{APós QUEIMADOR}

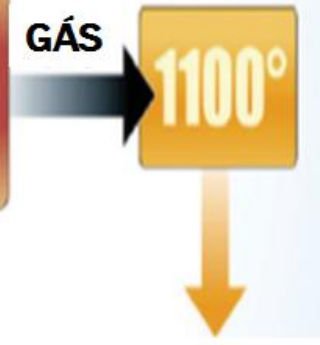

+ENERGIA

Fonte: (Larsen, 2009).

Ambos processos recuperam fibras de vidro e carbono com certa degradação, no entanto, ainda podem ser utilizados para aplicações em que há menor demanda de resistência mecânica, como é o caso da aplicação como material de isolamento térmico (Åkesson et al., 2012).

Comparando estes dois últimos processos descritos, o processo de pirólise apresenta melhores resultados quanto às propriedades mecânicas das fibras de vidro e carbono, pois há menor degradação 
delas, em relação ao processo de FBC, mas também produz resíduos e gases nocivos ao meio ambiente, incluindo o monóxido de carbono (CO), dióxido de carbono $\left(\mathrm{CO}_{2}\right)$ e o metano $\left(\mathrm{CH}_{4}\right)$ (Åkesson et al., 2012).

No entanto, esse processo ainda não é rentável, uma vez que todas essas técnicas de processamento térmico para as pás eólicas ainda exigem que haja a fragmentação do material em partes menores por meio de processamento mecânico, antes de serem alimentadas nos reatores; aumentando dessa forma o custo, o consumo de energia e as emissões de dióxido de carbono durante todo o processo (Ramirez-Tejeda et al., 2017).

\subsubsection{Processo químico}

A reciclagem química consiste na despolimerização, com formação de monômeros ou outros tipos de radicais úteis em decorrência à degradações planejadas, apresentando como resultado a diminuição da massa molar dos produtos formados. Geralmente, esse processo pode ser dividido em dois tipos, a termólise e a solvólise. Sendo que a solvólise ocorre, principalmente, com o emprego de solventes para gerar a despolimerização. Enquanto na termólise, a estrutura química do polímero é degradada pela ação do calor (Guerrero et al., 2011).

A recuperação da fibra de vidro e da resina epóxi ocorre com a utilização de fluidos supercríticos. São fluidos que se encontram em temperatura e pressão logo acima do ponto crítico, no qual o fluido se apresenta em uma única fase, com características combinadas, como a densidade do tipo líquido, poder de dissolução, difusividade e viscosidade gasosa (Beauson et al., 2016).

As principais vantagens dessa abordagem são o potencial de recuperação da resina epóxi e a capacidade de preservar as propriedades mecânicas das fibras de vidro ao final do processo. Embora ainda não ocorram reciclagens químicas de polímeros termorrígidos em nível industrial, alguns produtos químicos perigosos têm sido usados em desenvolvimento de testes, como é o caso do ácido nítrico e do paraformaldeído. A exposição a esses produtos químicos pode causar doenças respiratórias, em casos mais sérios, até cancer nasal, além de causar distúrbios dermatológicos graves. Apesar desse processo conseguir manter a propriedade mecânica dos materiais reaproveitados, os gases tóxicos que são liberados no processo acabam limitando sua atratividade (Ramirez-Tejeda et al., 2017).

A seguir é apresentado um quadro resumo de seção visando responder o questionamento proposto em RQ2. 
Quadro 2 - Processos de aproveitamento dos resíduos de pás eólicas

\begin{tabular}{|c|c|c|c|}
\hline Tipos & Técnica & Resultados & Particularidades \\
\hline Mecânico & $\begin{array}{l}\text { Moagem do } \\
\text { material }\end{array}$ & $\begin{array}{l}\text { Resíduos particulados utilizados como } \\
\text { reforço constituinte de novas } \\
\text { matrizes poliméricas }\end{array}$ & $\begin{array}{l}\text { - Partículas com propriedades } \\
\text { mecânicas inferiores } \\
\text { - Baixo custo-benefício (baixo valor do } \\
\text { material de reuso e custo elevado das } \\
\text { operações) } \\
\text { - Riscos à saúde humana em razão da } \\
\text { poeira gerada nos processos }\end{array}$ \\
\hline Térmico & $\begin{array}{l}\text { Incineração do } \\
\text { material, pirólise ou } \\
\text { combustão em leito } \\
\text { fluidizado }\end{array}$ & $\begin{array}{l}\text { Recuperação das fibras para reuso em } \\
\text { novos compósitos, bem como a } \\
\text { queima do polímero, gerando energia } \\
\text { a ser utilizada em outros processos }\end{array}$ & $\begin{array}{l}\text { - Recuperação de material e energia } \\
\text { - Economia de espaço físico } \\
\text { - Produção de gases tóxicos }\end{array}$ \\
\hline Químico & $\begin{array}{l}\text { Termólise ou } \\
\text { solvólise }\end{array}$ & $\begin{array}{l}\text { Despolimerização do compósito e } \\
\text { recuperação das fibras de vidro }\end{array}$ & $\begin{array}{l}\text { - Diminuição da massa molar dos } \\
\text { produtos formados } \\
\text { - Preservação da propriedades } \\
\text { mecânicas das fibras } \\
\text { - Liberação de gases tóxicos nos } \\
\text { processos }\end{array}$ \\
\hline
\end{tabular}

Fonte: Elaborado pelos autores.

\subsection{RQ3. Em quais aplicações os resíduos de pás eólicas podem ser utilizados?}

A maioria dos métodos para reciclagem de resíduos de pás eólicas foi desenvolvido envolvendo processos químicos, térmicos ou mecânicos para a recuperação das fibras, como a trituração das fibras de vidro em pó ou pequenos fragmentos, para usá-los como enchimento na produção de novos materiais. Além disso, os resíduos de fibras de vidro podem ser incinerados a alta temperatura para produzir energia ou reduzir o volume de resíduos (Yazdanbakhsh et al., 2018).

Entre os processos acima mencionados, a reciclagem mecânica das fibras de vidro é uma opção atraente, pois tem a menor demanda de energia dentre os processos e não envolve processos químicos. A energia necessária para a reciclagem mecânica é entre 0,5\% e 5\% do que é necessário para reciclagem química e entre 0,4\% e 16\% da energia usada para reciclagem térmica (pirólise) (Yazdanbakhsh et al., 2018).

Entre as alternativas propostas para a reciclagem dos resíduos de pás eólicas também apresenta-se a reutilização dos compósitos das lâminas trituradas implementadas para o reforço de compósitos poliméricos termorrígidos (Beauson et al., 2016).

No estudo inicial de Beauson et al. (2014), os resíduos triturados das turbinas eólicas foram incorporados na fabricação de novos compósitos poliméricos termorrígidos, com matriz do tipo poliéster insaturado, por meio do processo de infusão à vácuo, para que fosse permitida a fabricação de compósitos com uma quantidade controlada dos resíduos triturados.

Esses compósitos apresentaram falhas prematuras como, por exemplo, grandes fissuras devido ao descolamento na interface matriz / fibras das superfícies dos compósitos triturados. Indicou-se, então, que a baixa força de ruptura e tensão das composições foi devida à ligação insuficiente entre os 
componentes dos resíduos triturados e a nova matriz de poliéster. Para resolver este problema, a aplicação de um tratamento físico ou químico dos resíduos triturados ou o uso de uma resina alternativa, como a epóxi, para melhorar a ligação pode ser investigada (Beauson et al., 2014).

Com relação às fibras de vidro recuperadas, a extração em larga escala para recuperar todas as camadas de tecidos ou mantas de fibras de vidro e transformar em um novo composto laminado pode ser relevante, especialmente se o redimensionamento for possível (Beauson et al., 2014).

Os resíduos das pás eólicas também podem ser utilizados como agentes de reforço na fabricação de polímeros inorgânicos, reduzindo assim os custos da produção de geopolímeros em comparação à utilização de outras fibras comerciais. O uso da fibra de vidro reciclada consegue controlar o desempenho mecânico dos polímeros inorgânicos, por exemplo, com maiores quantidades aumentando a resistência à compressão e à tração. Além disso, as fibras de vidro aumentam a ductilidade pós-fissuração dos polímeros inorgânicos, impedindo seu completo colapso, o que pode ampliar a faixa de aplicação do polímero inorgânico (Novais et al., 2017).

Os resultados de um estudo da implementação de elementos discretos de pás de turbinas eólicas mecanicamente recicladas em concreto, realizado por Yazdanbakhsh (2018), em que materiais compósitos de polímero reforçado com fibras de vidro foram processados mecanicamente em elementos delgados denominados "agulhas". Na Figura 8 está apresentada uma fotografia de várias destas "agulhas" com diâmetro médio de $6 \mathrm{~mm}$ e comprimento de $100 \mathrm{~mm}$. Agulhas eficientes podem ser produzidas selecionando materiais com alto módulo de Young e resistência à tração e ao cisalhamento; quando comparadas às fibras, constituem um número muito menor de elementos por volume; e possuem alta rigidez à flexão. Portanto, estas "agulhas" são menos propensas a se aglomerar e podem ser usadas em altas proporções volumétricas (Yazdanbakhsh et al., 2018).

Figura 8 - Agulhas de $6 \mathrm{~mm}$ de diâmetro e $100 \mathrm{~mm}$ de comprimento

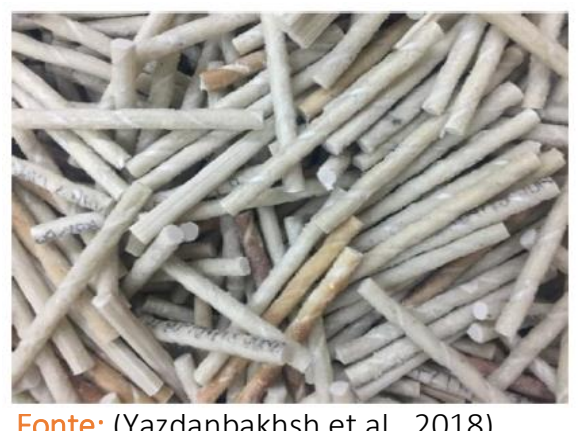

Fonte: (Yazdanbakhsh et al., 2018).

Estas "agulhas" foram usadas para substituir 5\% e 10\% do agregado graúdo, em volume, em misturas de concreto, que foram testadas para investigar uma série de propriedades importantes do concreto fresco e endurecido. Foi descoberto que as "agulhas" não afetam negativamente a estabilidade e a capacidade de trabalho do concreto fresco. Embora a incorporação das "agulhas" não 
tenha um efeito notável na resistência à compressão, tração e flexão do concreto, resultaram em um aumento significativo na capacidade de absorção de energia (tenacidade) (Yazdanbakhsh et al., 2018).

A seguir é apresentado um quadro resumo de seção visando responder o questionamento proposto em RQ3.

Quadro 3-Aplicações dos resíduos de pás eólicas

Algumas aplicações em que os resíduos das pás eólicas vêm sendo testados são:

- Enchimento na produção de novos compósitos

- Reforço na moldagem de novos compósitos

- Reforço de polímeros inorgânicos

- Produção de energia por combustão

Fonte: Elaborado pelos autores.

\section{Conclusão}

Vários estudos sobre o aproveitamento dos resíduos das pás de turbinas eólicas vêm sendo desenvolvidos nos últimos anos, devido à necessidade do crescimento de tecnologias limpas que visam minimizar os problemas ambientais. Dentre esses estudos foi percebida a dificuldade de se encontrar processos de aproveitamento de resíduos que sejam realmente limpos, uma vez que demandam uma grande quantidade de energia e/ou alto custo financeiro. Além disso, alguns processos têm como desvantagem a emissão de dióxido de carbono, um dos gases causadores do efeito estufa.

Os processos mais utilizados são o mecânico, o energético e o químico, nos quais os resíduos das pás eólicas são reprocessados e reincorporados em novos ciclos produtivos, seja na forma de energia gerada por combustão de seus elementos, seja na forma de insumo para servir de reforço em novos compósitos.

No entanto, as aplicações desses resíduos reciclados necessitam de mais investigação, pois apresentam baixos valores de propriedades mecânicas para serem incorporados na fabricação de novos materiais, como por exemplo, na incorporação em concreto e em polímeros termorrígidos, necessitando também de tratamento prévio para que seja viável essa aplicabilidade.

Embora tais medidas venham sendo aplicadas para os resíduos do segmento eólico, elas ainda são relativamente pequenas quando comparadas às estimativas da quantidade de material a ser descartado nos próximos 20 anos, período em que os primeiros grandes parques 
eólicos começarão a ser desmontados. Deste modo, muito ainda deve ser estudado a fim de encontrar soluções adequadas para tratar estes materiais como forma de reduzir os impactos negativos ao meio ambiente.

\section{Agradecimentos}

Os autores agradecem à Coordenação de Aperfeiçoamento de Pessoal de Nível Superior - Brasil (CAPES) - Código de Financiamento 001.

\section{Referências}

Åkesson, D., Foltynowicz, Z., Christéen, J., \& Skrifvars, M. (2012). Microwave pyrolysis as a method of recycling glass fibre from used blades of wind turbines. Journal of Reinforced Plastics and Composites, 31(17), 1136-1142. https://doi.org/10.1177/0731684412453512.

Andersen, N., Eriksson, O., Hillman, K., \& Wallhagen, M. (2016). Wind turbines' end-of-life: Quantification and characterisation of future waste materials on a national level. Energies, $9(12)$. https://doi.org/10.3390/en9120999.

Andersen, P. D., Bonou, A., Beauson, J., \& Brønsted, P. (2014). Recycling of wind turbines. DTU International Energy Report 2014, 91-98.

Beauson, J., Lilholt, H., \& Brøndsted, P. (2014). Recycling solid residues recovered from glass fibrereinforced composites - A review applied to wind turbine blade materials. Journal of Reinforced Plastics and Composites, 33(16), 1542-1556. https://doi.org/10.1177/0731684414537131.

Beauson, J., Madsen, B., Toncelli, C., Brøndsted, P., \& Ilsted Bech, J. (2016). Recycling of shredded composites from wind turbine blades in new thermoset polymer composites. Composites Part $A$ : Applied Science and Manufacturing, 90, 390-399.

https://doi.org/10.1016/j.compositesa.2016.07.009.

Cherrington, R., Goodship, V., Meredith, J., Wood, B. M., Coles, S. R., Vuillaume, A., Kirwan, K. (2012). Producer responsibility: Defining the incentive for recycling composite wind turbine blades in Europe. Energy Policy, 47, 13-21. https://doi.org/10.1016/j.enpol.2012.03.076.

Goren, A., \& Atas, C. (2008). Manufacturing of polymer matrix composites using vacuum assisted resin infusion molding. Archives of Materials Science and Engineering, 34(2), 117-120.

Guerrero, P. C., Mancini, S. D., \& Toubia, C. M. (2011). Caracterização E Reciclagem Química Via Pirólise De Resíduos Da Fabricação De Pás Eólicas Characterization and Chemical Recycling By Pyrolysis of Waste From Wind Blades Manufacturing. HOLOS Environment, 147(112), 1519-8634. https://doi.org/http://dx.doi.org/10.14295/holos.v11i2.5627.

Larsen, K. (2009). Recycling wind. Reinforced Plastics, 53(1), 20-23,25. https://doi.org/10.1016/S00343617(09)70043-8.

Liu, P., \& Barlow, C. Y. (2017). Wind turbine blade waste in 2050. Waste Management, 62, 229-240. https://doi.org/229-240. 
Mamanpush, S. H., Li, H., Englund, K., \& Tabatabaei, A. T. (2018). Recycled wind turbine blades as a feedstock for second generation composites. Waste Management, 76, 708-714. https://doi.org/10.1016/j.wasman.2018.02.050.

Novais, R. M., Carvalheiras, J., Seabra, M. P., Pullar, R. C., \& Labrincha, J. A. (2017). Effective mechanical reinforcement of inorganic polymers using glass fi bre waste. Journal of Cleaner Production, 166, 343-349. https://doi.org/10.1016/j.jclepro.2017.07.242.

Ramirez-Tejeda, K., Turcotte, D. A., \& Pike, S. (2017). Unsustainable Wind Turbine Blade Disposal Practices in the United States. New Solutions : A Journal of Environmental and Occupational Health Policy: NS, 26(4), 581-598. https://doi.org/10.1177/1048291116676098.

Tranfield, D., Denyer, D., \& Smart, P. (2003). <Tranfield_et_al-2003-

British_Journal_of_Management.pdf>, 14, 207-222. https://doi.org/10.1111/1467-8551.00375.

Yazdanbakhsh, A., Bank, L. C., Rieder, K. A., Tian, Y., \& Chen, C. (2018). Concrete with discrete slender elements from mechanically recycled wind turbine blades. Resources, Conservation and Recycling, 128(June 2017), 11-21. https://doi.org/10.1016/j.resconrec.2017.08.005. 